University of Louisville

ThinkIR: The University of Louisville's Institutional Repository

Faculty Scholarship

$7-2010$

\title{
The University of Louisville School of Music Guest Book : from local treasure to online resource.
}

James Procell

University of Louisville, jjproc01@louisville.edu

Rachel Howard

University of Louisville, rachel.howard@louisville.edu

Follow this and additional works at: https://ir.library.louisville.edu/faculty

Part of the Cataloging and Metadata Commons, and the Other Music Commons

\section{Original Publication Information}

This is a pre-copy-editing, author-produced PDF of an article accepted for publication in Music Reference Services Quarterly, volume 13, issue 1-2, in 2010, following peer review. The definitive publisherauthenticated version is available online at DOI: 10.1080/10588167.2010.494547.

This Article is brought to you for free and open access by ThinkIR: The University of Louisville's Institutional Repository. It has been accepted for inclusion in Faculty Scholarship by an authorized administrator of ThinkIR: The University of Louisville's Institutional Repository. For more information, please contact thinkir@louisville.edu. 


\section{The University of Louisville School of Music Guest Book : From Local Treasure to Online Resource}

\section{By James Procell and Rachel Howard}

\section{Shortened version of title: Univ. of Louisville Guest Book}

Abstract: A collaboration between the University of Louisville's Dwight Anderson Music Library and Digital Initiatives Department has resulted in the digitization of the University of Louisville School of Music Guest Book. Begun in 1949, the book contains signatures and handwritten messages from many of the most well-known musicians of the twentieth and twenty-first centuries. This article describes the approach to scanning, cataloging, indexing, and providing full-text searchable online access to the guest book using CONTENTdm digital media management software. It addresses resource and technical challenges encountered and overcome.

An exciting collaboration between the University of Louisville Dwight Anderson Music Library and the university's Digital Initiatives department has resulted in the digitization of the University of Louisville School of Music Guest Book. The guest book digitization project highlights the rich and varied history of music in Louisville, Kentucky. The book began in 1949 as the official guest book for the Louisville Orchestra Commissioning Project. Early signatures in the book are from composers whose works were premiered by the orchestra, as well as attendees at the premiere concerts. Some of the most well-known composers of the $20^{\text {th }}$ century signed the book during this time, including Aaron Copland, Paul Hindemith, and Dmitri Shostakovich. The book evolved into the official guest book for the School of Music at the 
University of Louisville. Over the years, many visitors to the School of Music have signed the book, including composers, performers, lecturers, and politicians. Covering more than 60 years of musical history, the book now contains more than 1,000 signatures from some of the most well-known musicians of the $20^{\text {th }}$ and $21^{\text {st }}$ centuries.

\section{About the University of Louisville Digital Collections and Background on the Project}

The University of Louisville (UofL) debuted its Digital Collections website at http://digital.library.louisville.edu in May 2007, with two collections of images of local and regional interest, drawn from the Special Collections unit in the William F. Ekstrom (main) library and the University Archives and Records Center. Internal and external reaction to the site was positive, generating interest from other UofL libraries in digitizing their rare and unique items for inclusion in the Digital Collections, but resources to support the scanning and metadata creation efforts took more time to build. The Digital Initiatives department, created following the receipt of a Library Services Technology Act grant to purchase CONTENTdm digital media management software in 2005, initially consisted of one Digital Initiatives Librarian, hired in August 2006. A Metadata Librarian, reporting to the Digital Initiatives Librarian, came on board in April 2008. By 2009, the Louis D. Brandeis Law Library, the Margaret M. Bridwell Art Library, and the Kornhauser Health Sciences Library had each launched a digital collection, leaving the Dwight Anderson Music Library as the only UofL library lacking a presence in the Digital Collections. This was due to a combination of factors, including staffing, equipment, copyright issues, and funding. In the summer of 2009, the Music Librarian and Digital Initiatives Librarian met to discuss the possibility of digitizing a collection held by the Music 
Library. Collections that were candidates for digitization were examined, and it was determined that the guest book would make an outstanding digital project. With the University Libraries' legal advisor's assurance that making signatures widely available would not violate privacy or copyright issues, the proposed project was approved.

The initial issue involving the digitization of the book was lack of funding. The breakthrough on that front was the receipt of a small amount of funds from the Digital Initiatives Librarian and Metadata Librarian's participation in a statewide grant-funded project. This funding did not have to be used for the statewide project; it was considered repayment for the time already spent by the Digital Initiatives staff, who immediately asked that it be used to fund a student worker to scan large-format materials using the underutilized overhead scanner.

\section{Digitization Workflow}

The overhead scanner used in this project was a Linhof Kardan M camera with $135 \mathrm{~mm}$ Rodenstock lens mounted on a copy stand, illuminated by 150 -watt bulbs in four light stands. The BetterLight scan back inserted into the camera connects to a 40-gigabyte hard drive, which is in turn connected to a PC running ViewFinder software. When an item is placed on the copy stand, the camera can be raised or lowered to frame the image, then focus, tone, color, and exposure can be adjusted using the ViewFinder software. This setup makes it possible to scan large (up to $30 \mathrm{x} 40$-inch) items which do not fit on a flatbed scanner, and fragile or bound items which would have been damaged by being pressed face-down onto the glass of a flatbed scanner. It produces high-quality, high-resolution uncompressed color scans, but requires much more time and attention to detail in setup than occurs with a flatbed scanner. Thus, the optimal workflow would be to train one person, who would then work for large blocks of time (making the daily 
setup time pay off in productivity), and to triage projects so that items of the same size and shape can be scanned consecutively, minimizing the time spent adjusting the numerous scanner settings.

The School of Music Guest Book was the perfect training project for the new student employee starting at the beginning of Fall semester 2009. It was too thick to be safely scanned on a flatbed scanner, requiring the use of the overhead scanner, but the uniform page size and coloration would allow for consecutive page scanning without excessive changes in the camera settings. In order to further streamline the scanning, as well as to accommodate the fact that only the right-hand pages of the book were numbered, even though both sides of many pages were signed, the decision was made to always scan the facing pages as one image, saved under a filename corresponding to the number in the upper right-hand corner. This meant that sometimes blank pages were scanned because they faced a signed page.

The scanning workflow had to occasionally be modified, as the book was still a living document, intended to be signed by all visitors to the School of Music, including guest artists, composers, lecturers, and dignitaries. Inevitably, some visits were scheduled during the time period in which scanning occurred. Fortunately, the Music Library staff kept the Digital Initiatives staff informed of these visits, so that a good stopping point could be reached before the guest book was retrieved, a smaller scanning project could be completed by the student during its absence, and a time for the book's return could be established.

\section{Indexing, Metadata, and Site Launch}

Once scanning was completed, the next step was to import the files into the CONTENTdm database software. Although more manipulation of the files and the information 
about them can be done within CONTENTdm after the import, the greatest efficiency can be achieved by making certain decisions ahead of time. One such decision involved the display format of the files. They were scanned as uncompressed TIFFs (Tagged Image File Format) at 600 pixels per inch, in accordance with best practices for archival master files. However, a smaller, more flexible format was needed for accessing the pages via the Web. CONTENTdm can ingest the full-resolution files and create derivative files in JPEG (Joint Photographic Experts Group) or JPEG2000 format for display. For this project, JPEG2000 made the most sense: its wavelet-based compression allowed for the creation of relatively small files that could nonetheless be zoomed in for a closer look at details, such as a signature or detailed handwritten message.

Another decision involved the searchability of the words on each page scanned. OCR (Optical Character Recognition) software is built into CONTENTdm; however, handwritten pages such as those in the guest book cannot be readily interpreted by machines. Fortunately, the Music Library staff had already anticipated the desire to search the book by name, even in a predigital age. They previously created and continually updated an index of signatories in alphabetical order by name, as well as a document annotating the names with biographical details. These files were supplied to the Digital Initiatives Librarian in, respectively, Microsoft Excel 2007 (.xlsx) and Microsoft Word 2007 (.docx) formats. The Digital Initiatives Librarian reformatted the name index spreadsheet so that it was also sorted by page, copied all three files into the same directory as the scanned page images, and attempted to import all files as a batch. The end result was a compound object, arranged in order by filename, with the guest book pages falling into the order in which they appeared in the original and the index and annotation pages appearing at the end. 
The initial attempt to import the index files did not work, due to the unforeseen complication that CONTENTdm did not yet support Microsoft Office 2007 formats. The Digital Initiatives Librarian converted the files to PDF (Portable Document Format) using the conversion tools built into Microsoft Office 2007, and was able to successfully import all of the files. However, because of the mixed file types (JPEG2000 for all images within the guest book, and PDF for all additional pages), the software did not automatically display the navigation thumbnail viewer, a handy tool for taking advantage of the zoom-in functionality of JPEG2000 files. In order to assist users with navigating the files, an instruction page, in PDF format, was added to the beginning of the compound object.

The Digital Initiatives Librarian created metadata for the guest book within the CONTENTdm Project Client, based on the data dictionary used for all other Digital Collections projects (http://digital.library.louisville.edu/cdm4/cookbook.pdf) and focusing on documentlevel information rather than page-level information, except for the two PDF index files, since their title, creator, and format information differed from that of the scanned images.

A homepage for the Dwight Anderson Music Library's digital collections was designed by the university's Web Services Librarian, and the site was launched in January 2010, following a short delay due to software upgrades and semester break. It will require ongoing maintenance, as pages with new signatures will need to be scanned, and the indices and annotated document updated accordingly — once a year seems a reasonable timeframe. In the meantime, the Music Library is investigating other collections for inclusion in Digital Collections.

Covering a rich and varied musical history and containing signatures from some of the most well-known musicians of our time, the digitization of the University of Louisville School of 
Music Guest Book has preserved it for generations to come. The book can be viewed online at http://digital.library.louisville.edu/collections/music/.

Figure 1 (insert image 1 here)

The cover of the University of Louisville School of Music Guest Book

Figure 2 (insert image 2 here)

A scanned image of a page from the book. Included on this page from 1954 are signatures from Johana Harris, Hugo Zelzer, Leo Lerman, Quincy Porter, Peggy Glanville-Hicks, Alexander Tcherepnin, Jenő Takács, Alfred Reed, Henry Cowell, and Ulysses Kay.

James Procell is the Assistant Director of the Dwight Anderson Music Library at the University of Louisville.

Rachel Howard is the Digital Initiatives Librarian at the University of Louisville. 